Article

\title{
Comparison of Temperature Dependent Carrier Transport in FinFET and Gate-All-Around Nanowire FET
}

\author{
Soohyun Kim ${ }^{1,2}$, Jungchun Kim ${ }^{2}$, Doyoung Jang ${ }^{1}$, Romain Ritzenthaler ${ }^{1}$, Bertrand Parvais ${ }^{1,3}$, \\ Jerome Mitard $^{1}$, Hans Mertens ${ }^{1}$, Thomas Chiarella ${ }^{1}$, Naoto Horiguchi ${ }^{1}$ and Jae Woo Lee ${ }^{2, *}$ \\ 1 IMEC, Kapeldreef 75, 3001 Leuven, Belgium; tn5227@korea.ac.kr (S.K.); Doyoung.Jang@imec.be (D.J.); \\ Romain.Ritzenthaler@imec.be (R.R.); Bertrand.Parvais@imec.be (B.P.); Jerome.Mitard@imec.be (J.M.); \\ Hans.Mertens@imec.be (H.M.); Thomas.Chiarella@imec.be (T.C.); Naoto.Horiguchi@imec.be (N.H.) \\ 2 ICT Convergence Technology for Health \& Safety and Department of Electronics and Information \\ Engineering, Korea University, Sejong-ro, Sejong 2511, Korea; jungchun94@korea.ac.kr \\ 3 Department ETRO, Vrije Universiteit Brussels (VUB), 1050 Brussels, Belgium \\ * Correspondence: orion627@korea.ac.kr
}

Received: 3 April 2020; Accepted: 18 April 2020; Published: 24 April 2020

\begin{abstract}
The temperature dependent carrier transport characteristics of n-type gate-all-around nanowire field effect transistors (GAA NW-FET) on bulk silicon are experimentally compared to bulk fin field effect transistors (FinFET) over a wide range of temperatures $\left(25-125^{\circ} \mathrm{C}\right)$. A similar temperature dependence of threshold voltage $\left(V_{T H}\right)$ and subthreshold swing $(S S)$ is observed for both devices. However, effective mobility $\left(\mu_{\text {eff }}\right)$ shows significant differences of temperature dependence between GAA NW-FET and FinFET at a high gate effective field. At weak $N_{i n v}\left(=5 \times 10^{12} \mathrm{~cm}^{2} / \mathrm{V} \cdot \mathrm{s}\right)$, both GAA NW-FET and FinFET are mainly limited by phonon scattering in $\mu_{\text {eff. }}$. On the other hand, at strong $N_{i n v}\left(=1.5 \times 10^{13} \mathrm{~cm}^{2} / \mathrm{V} \cdot \mathrm{s}\right)$, GAA NW-FET shows 10 times higher $d \mu_{\text {efff }} / d T$ and 1.6 times smaller mobility degradation coefficient $(\alpha)$ than FinFET. GAA NW-FET is less limited by surface roughness scattering, but FinFET is relatively more limited by surface roughness scattering in carrier transport.
\end{abstract}

Keywords: GAA NW-FET; FinFET; temperature dependence; effective mobility; surface roughness scattering

\section{Introduction}

For several years, fin field effect transistors (FinFETs) have been used industry to continue CMOS down-scaling. However, as FinFETs also have been look forward to being further scaled, critical issues such as drain-induced barrier lowering, threshold voltage $\left(V_{T H}\right)$ roll-off and parasitic resistance occur, etc. [1]. In order to alleviate these issues, the gate-all-around nanowire field effect transistors (GAA NW-FEsT) have been recently proposed as a promising device to replace FinFETs, due to their superior gate control $[2,3]$. The better electrostatic gate control provided by the surrounding gate enables a more aggressive gate length scaling than FinFETs [4-6]. However, advanced fabrication technologies remain challenging, e.g., the GAA structure formation [7] and doping process [8] to restrain a naturally formed parasitic channel based on bulk FinFETs. Such device fabrication directly affects key device parameters $\left(V_{T H}\right.$, subthreshold swing (SS) and effective mobility $\left(\mu_{\text {eff }}\right)$, etc.). Furthermore, the electrical characteristics of semiconductors such as band gap [9], carrier density [10], mobility [11], velocity saturation [12], $V_{T H}$ [13], and leakage current [14] depend strongly on the temperature resulting in a change of circuit performance as a function of the operating temperature. Therefore, it is important to explore the possible degradation at a high temperature which might lead to performance degradation 
in a hot temperature corner. It is helpful to understand and to model the temperature dependence of GAA devices to enable the design of circuits in this technology.

In this study, we investigated the high temperature characteristics of vertical 2-stacked n-channel metal oxide semiconductor (NMOS) GAA NW-FETs and FinFETs in order to understand the potential differences between the two devices.

\section{Materials and Methods}

The cross-sectional transmission electron microscopy (TEM) images [8,15] of the devices under test are shown in Figure 1. Both GAA NW-FETs and FinFETs were fabricated using the high-k replacement metal gate (HK-RMG) process $[7,16,17]$. The diameter of nanowire $\left(D_{n w}\right)$ is $8 \mathrm{~nm}$ for GAA NW-FETs. In the case of FinFETs, the fin width $\left(W_{\text {fin }}\right)$ is $5 \mathrm{~nm}$ and the fin height $\left(H_{\text {fin }}\right)$ was $26 \mathrm{~nm}$.

(a) GAA NW-FET

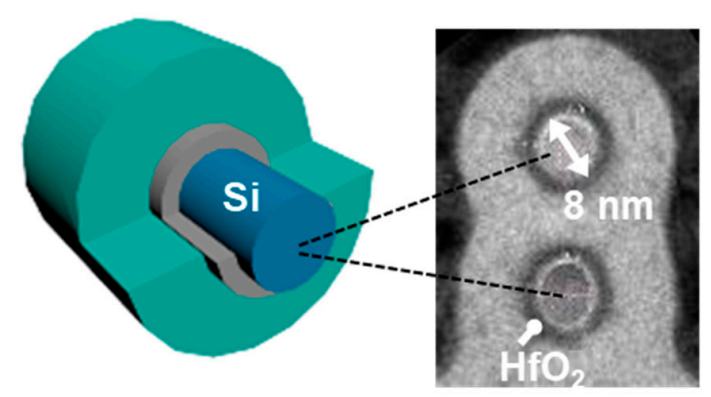

(b) FinFET

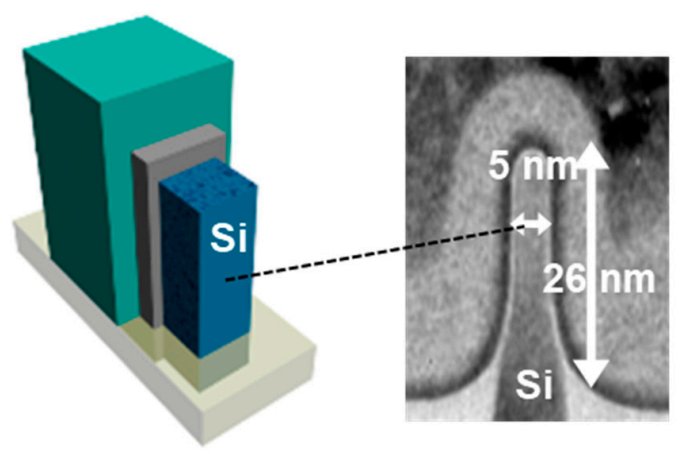

Figure 1. TEM cross-sectional images of NMOS: (a) gate-all-around nanowire field effect transistors (GAA NW-FETs); and (b) fin field effect transistors (FinFETs). Two nanowires are stacked in GAA NW-FETs.

Both GAA NW-FETs and FinFETs were fabricated based on a conventional bulk FinFETs process flow [15] with the following particularities in the case of GAA NW-FETs, as shown in Figure 2. First, in order to suppress the short channel effect, a ground plane (GP) isolation implant was used [8]. Implanted boron reduced the punch through via a parasitic channel underneath the bottom of the nanowire so that it improves the gate control in the subthreshold region. The second difference is the channel formation process. For fin formation on both devices, a self-aligned double patterning (SADP) process is conducted using SiN spacers while maintaining uniform shallow trench isolation (STI) filling. To make nanowires, SiGe/Si/SiGe/Si epitaxial layers were grown before the SADP process, and the sacrificial SiGe layer was removed with the vapor $\mathrm{HCl}$ etch process before the HK-RMG process. Furthermore, the temperature of the STI densification step was reduced from 1050 to $750{ }^{\circ} \mathrm{C}$ to avoid $\mathrm{SiGe} / \mathrm{Si}$ intermixing and a consequent loss of nanowire shape controllability [18]. In this study, gate lengths $L_{G}=30 \mathrm{~nm}$ and $70 \mathrm{~nm}$ were used for the electrical characterization.

The Keysight B1500A was used for the electrical measurements. The gate-source bias $\left(V_{G S}\right)$ was swept from -0.5 to $1.5 \mathrm{~V}$ (step $=50 \mathrm{mV}$ ) in the linear region at $V_{D S}=50 \mathrm{mV}$. The electrical characterizations were carried out under various temperature conditions from 25 to $125^{\circ} \mathrm{C}$. 


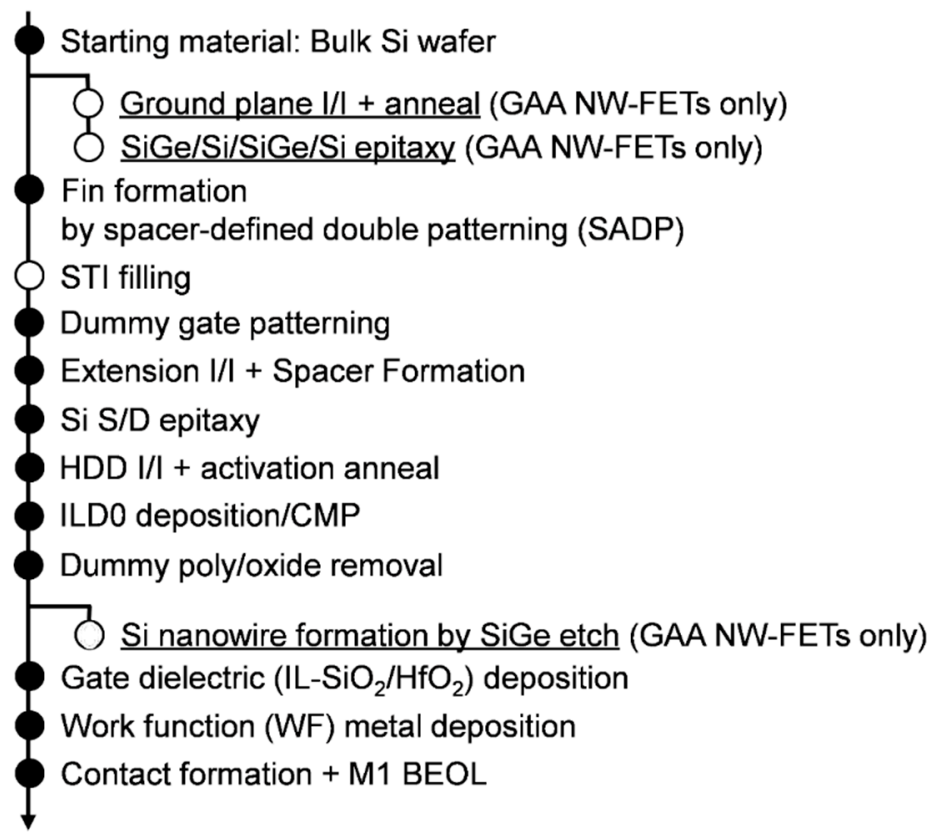

Figure 2. Fabrication process flow in FinFET and GAA NW-FET.

\section{Results}

The drain current $\left(I_{D S}\right)$ at different temperature conditions are shown for NMOS GAA NW-FET (Figure 3a) and FinFET (Figure 3b). A slightly higher $I_{D S}$ is observed for GAA NW-FET $\left(\sim 6 \%\right.$, at $\left.25^{\circ} \mathrm{C}\right)$ compared to FinFET. For both GAA NW-FET and FinFET, the $I_{D S}$ decreased as the temperature increased at the same overdrive voltage $\left(V_{O V}=V_{G S}-V_{T H}\right)$, which shows the phonon scattering limited mobility behavior [19].

(a)

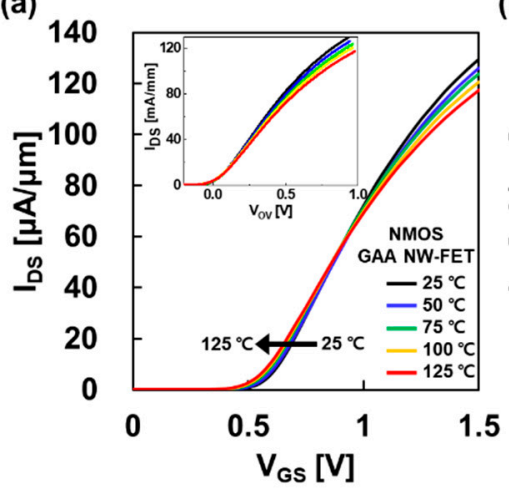

(b)

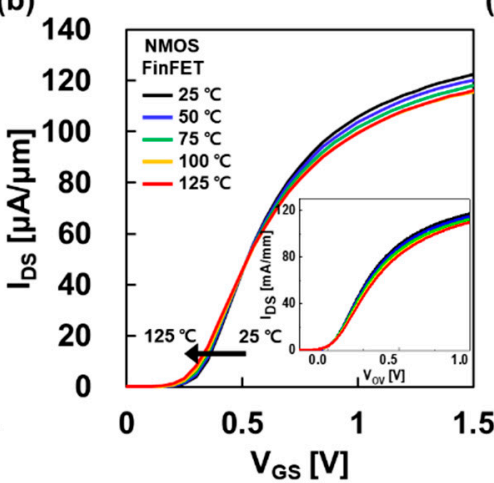

(c)

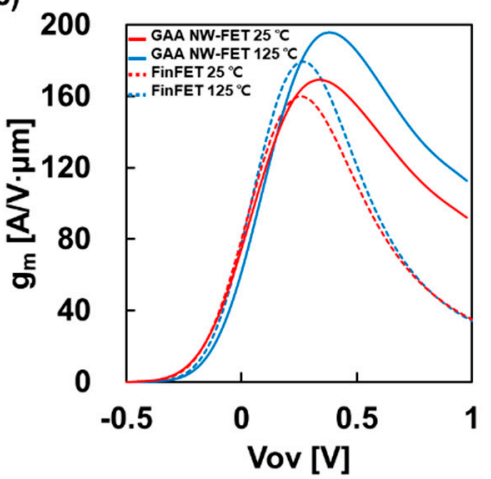

Figure 3. Measured $I_{D S^{-}} V_{G S}$ curves (linear region, $V_{D S}=50 \mathrm{mV}$ ) under various temperature conditions from 25 to $125^{\circ} \mathrm{C}$ for (a) GAA NW-FET. (b) FinFET with $L_{G}=30 \mathrm{~nm}$. Insets: $I_{D S^{-}} V_{O V}\left(V_{O V}=V_{G S}-\right.$ $\left.V_{T H}\right)$ curves. (c) $g_{m}-V_{G S}$ curves for GAA NW-FET and FinFET for 25 and $125^{\circ} \mathrm{C}$.

It can also be seen that $\mathrm{V}_{\mathrm{TH}}$ down-shifted from 0.56 to $0.52 \mathrm{~V}$ for GAA NW-FET and 0.30 to $0.27 \mathrm{~V}$ for FinFET as the measurement temperature increases. In Figure 3c, compared to the transconductance $\left(g_{m}\right)$ at different temperatures, FinFET and GAA NW-FET show the disparate degree of reduction at the same $V_{O V}$. For example, as the measurement of the temperature increases, the $g_{m}$ of FinFET and GAA NW-FET decreases $0.4 \%$ (from 127.1 to $126.6 \mu \mathrm{S} / \mu \mathrm{m}$ ) and $12.8 \%$ (from 188.2 to $164.1 \mu \mathrm{S} / \mu \mathrm{m}$ ) at $V_{O V}=0.5 \mathrm{~V}$, respectively. 
The temperature dependences of $V_{T H}$ for GAA NW-FET and FinFET are plotted using the maximum transconductance method [20] in Figure 4a.
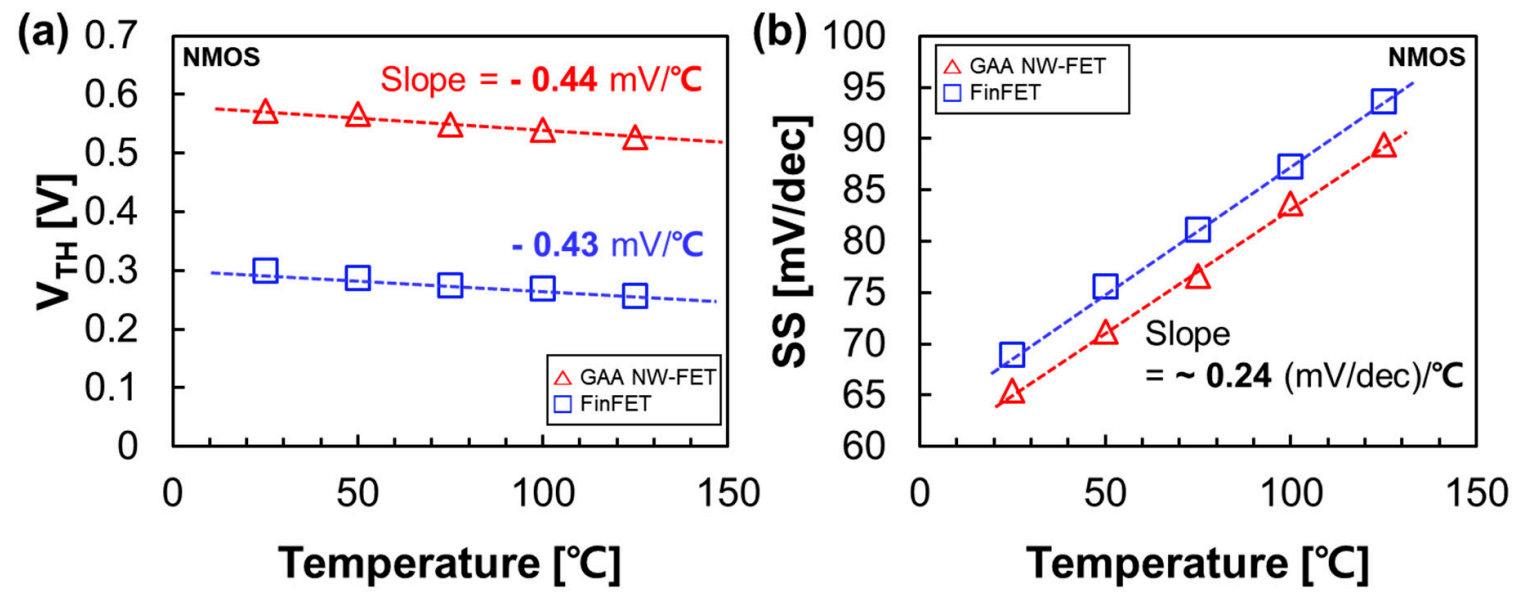

Figure 4. (a) $V_{T H}$ as a function of temperature for GAA NW-FET and FinFET from Figure 3. Similar temperature sensitivities of $V_{T H}$ are observed for both GAA NW-FET and FinFET. (b) Subthreshold swing (SS) as a function of temperature also shows same slopes for both GAA NW-FET and FinFET.

The $V_{T H}$ as a function of temperature can be explained by the following equation [13]:

$$
\frac{d V_{T H}}{d T}=\frac{d \varnothing_{F}}{d T}\left[k \sqrt{\frac{q \varepsilon_{s i} N_{e f f}}{\varnothing_{F} C_{o x}{ }^{2}}}+2+\frac{C_{i t}}{C_{o x}}\right]
$$

where $\varnothing_{F}[\mathrm{eV}]$ is the Fermi potential, $q[\mathrm{C}]$ the electron charge, $\varepsilon_{s i}[\mathrm{~F} / \mathrm{cm}]$ the silicon permittivity, $N_{e f f}\left[\mathrm{~cm}^{-3}\right]$ the effective doping level, $C_{o x}\left[\mathrm{~F} / \mathrm{cm}^{2}\right]$ the oxide capacitance, and $C_{i t}\left[\mathrm{~F} / \mathrm{cm}^{2}\right]$ the interface trap density, respectively, in Equation (1). The fitting parameter $k$ is 1 for partially depleted devices and closed to 0 for fully depleted channels. The $V_{T H}$ is predicted to decrease at a high temperature due to the reduction of $\varnothing_{F}$ [21]. The $\varnothing_{F}$ decreased by excited carriers from the valence band to conduction band when the temperature rises. In this study, a similar temperature dependent $V_{T H}$ is observed between GAA NW-FET $\left(d V_{T H} / d T=-0.44 \mathrm{mV} /{ }^{\circ} \mathrm{C}\right)$ and FinFET $\left(d V_{T H} / d T=-0.43 \mathrm{mV} /{ }^{\circ} \mathrm{C}\right)$. In the case of bulk planar NMOS, $d V_{T H} / d T$ was approximately $-0.7 \mathrm{mV} /{ }^{\circ} \mathrm{C}$ [22]. For the GAA NW-FET and FinFET, the lowering of $d V_{T H} / d T$ is attributed to the fully depleted channel with the thinning of the channel.

\section{Discussion}

To understand the temperature dependence of $S S$, the parameter of the on-off switching capability, the following equation is used [23]:

$$
S S \approx \frac{k_{B} T}{q} \ln 10\left[1+\frac{\left(C_{D}+C_{i t}\right)}{C_{o x}}\right]
$$

Here, $C_{D}$ is the depletion capacitance, $k_{B}$ the Boltzmann's constant, and $T$ the temperature, respectively. The channel region of GAA NW-FET and FinFET is sufficiently shallow $\left(D_{n w}=8 \mathrm{~nm}\right.$ for GAA NW-FET and $W_{f i n}=5 \mathrm{~nm}$ for FinFET) so that the channel is fully depleted. Thus, the depletion charge $\left(Q_{D}\right)$ of these devices are not a function of $V_{G}$, and $C_{D}\left(=d Q_{D} / d V_{G}\right)$ is negligible [23]. GAA NW-FET shows smaller $S S$ at any temperature condition (SSs of GAA NW-FET and FinFET are about 65 and $69 \mathrm{mV} / \mathrm{dec}$ at $25^{\circ} \mathrm{C}$, respectively). The large $S S$ is induced by poor gate control, punch through, and $C_{i t}$. Similar to $d V_{T H} / d T$, the $d S S / d T$ for both devices is approximately equal to $\sim 0.24 \mathrm{mV} / \mathrm{dec} /{ }^{\circ} \mathrm{C}$, as shown in Figure $4 \mathrm{~b}$. Thus, the identical slope of Figure $4 \mathrm{~b}$ shows $\ln 10\left[1+C_{i t} / C_{o x}\right]$ is same for both devices. By considering identical $d S S / d T$ and similar $d V_{T H} / d T$ between GAA NW-FET 
and FinFET, $C_{i t}$ is also regarded as identical $\left(C_{i t}=6.28 \times 10^{-7} \mathrm{~F} / \mathrm{cm}^{2}\right.$ when the capacitance equivalent thickness was $1.1 \mathrm{~nm}$ for both devices). In Figure 5, the temperature dependent $\mu_{e f f}$ is investigated for $L_{G}=70 \mathrm{~nm}$. The $\mu_{e f f}$ was experimentally extracted from [24]:

$$
\mu_{e f f}=\left.\frac{L_{e f f}}{W_{e f f}} \frac{g_{D}}{q N\left(V_{G S}\right)}\right|_{V_{D S} \rightarrow 50 \mathrm{mV}}
$$

where $g_{D}[\mathrm{~A} / \mathrm{V}]$ is the drain conductance, $V_{G S}$ the gate-source voltage, $V_{D S}$ the drain-source voltage, and $W_{\text {eff }}$ and $L_{e f f}$ the effective width and length of the channel, respectively. $q N\left(V_{G S}\right)$ was calculated in the strong inversion region assuming by $q N\left(V_{G S}\right)=C_{o x}\left(V_{G S}-V_{T H}\right)$.
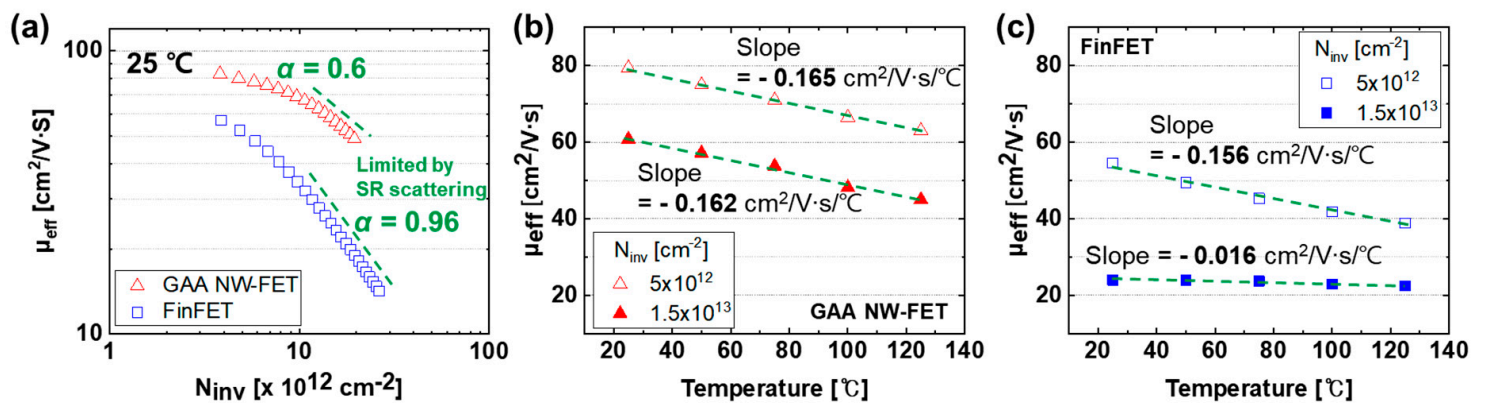

Figure 5. Effective mobility $\left(\mu_{e f f}\right)$ behavior comparison between GAA NW-FET and FinFET with $L_{G}=$ $70 \mathrm{~nm} ;(\mathbf{a}) \mu_{e f f}-N_{i n v}$. Temperature dependence of $\mu_{e f f}$ for (b) GAA NW-FET and (c) FinFET.

From Matthiessen's rule, the $\mu_{e f f}$ is composed of several mobility limited scattering mechanisms such as Coulomb, phonon, and surface roughness (SR) [25]. When a device is suffering from serious SR scattering, a large mobility degradation can be observed at high $V_{O V}$ compared to the mobility behavior limited by phonon scattering, etc. [26].

The mobility limited by SR scattering is analyzed quantitatively by the following relationship [11,27]:

$$
\mu_{S R} \propto \frac{E_{e f f}-\alpha}{\Delta^{2} \lambda^{2}}
$$

where $E_{\text {eff }}$ is the effective field across the channel, which can be substituted to $N_{i n v}$ proportional to $E_{\text {eff }}$, $\Delta$ the rms value of the $S R$, and $\lambda$ its correlation length. The $\mu_{S R}$ is inversely proportional to the mobility degradation coefficient $\alpha$. The extracted $\alpha$ of GAA NW-FET is 0.6 , which is smaller than that of FinFET (0.96). This means that less SR scattering is shown for GAA NW-FET compared to FinFET (Figure 5a). In addition, the $\mu_{S R}$ has weak temperature dependence compared to the mobility limited by phonon scattering [28]. GAA NW-FET (Figure 5b) shows a stronger temperature dependent $\mu_{\text {eff }}$ than FinFET (Figure 5c). These are investigated with two operating conditions: at weak $N_{i n v}=5 \times 10^{12}$ and strong $N_{i n v}=1.5 \times 10^{13} \mathrm{~cm}^{2} / \mathrm{V} \cdot \mathrm{s}$. At weak $N_{i n v}$, similar $d \mu_{e f f} / d T$ is observed between both devices $(-0.165$ for GAA NW-FET and $-0.156 \mathrm{~cm}^{2} / \mathrm{V} \cdot \mathrm{s} /{ }^{\circ} \mathrm{C}$ for FinFET) because the phonon scattering is dominant than the SR scattering at low $E_{e f f}$. At strong $N_{i n v}$, on the other hand, the $\mu_{e f f}$ of GAA NW-FET is further degraded for a rising temperature than FinFET. This is another evidence that FinFETs are suffering from the SR scattering than GAA NW-FETs $\left(-0.162\right.$ for GAA NW-FET and $-0.016 \mathrm{~cm}^{2} / \mathrm{V} \cdot \mathrm{s} /{ }^{\circ} \mathrm{C}$ for FinFET). At strong $N_{i n v}$, the $d \mu_{e f f} / d T$ is moderated approximately $18 \%$ compared to the weak $N_{i n v}$ region for GAA NW-FET, but it is dramatically changed (90\%) for FinFET. At $25^{\circ} \mathrm{C}$, the $\mu_{\text {eff }}$ of GAA NW-FET decreases by $23.4 \%$ between weak $N_{i n v}$ and strong $N_{i n v}$, whereas FinFET's decrease is more pronounced $(56.1 \%)$. At $V_{O V}=0.5 \mathrm{~V}$, the smaller $g_{m}$ for FinFET $\left(=127.1\right.$ at $25^{\circ} \mathrm{C}$, but $188.2 \mu \mathrm{S} / \mu \mathrm{m}$ in the case of GAA NW-FET) is consistent with such different degrees of SR scattering for both devices.

The reduced SR scattering for GAA NW-FET could be assisted by a round-shaped NW channel formation process using a vapor $\mathrm{HCl}$ etch. The surface roughness of GAA NW-FET channel is softened 
by the vapor $\mathrm{HCl}$ etching process. Thus, at a large $V_{O V}$, the relatively higher value and slower degradation of $g_{m}$ (in Figure 3c) and $\mu_{e f f}$ (in Figure 5a) in GAA NW-FET could be from the suppression of SR scattering in the channel compared to FinFET.

\section{Conclusions}

In this work, the temperature dependent characteristics of NMOS GAA NW-FETs have been investigated comparing with FinFET. In GAA NW-FET, the experimental $I_{D S^{-}} V_{G S}$ characteristics show higher $I_{D S}$ and better $S S$ than in FinFET from 25 to $125^{\circ} \mathrm{C}$. The modulation trend of $V_{T H}$ and $S S$ with temperature is not significantly different between GAA NW-FET and FinFET. At weak $N_{i n v}$, $\mu_{e f f}$ is mainly limited by phonon scattering for both GAA NW-FET and FinFET. However, at strong $N_{i n v}$, the $\mu_{e f f}$ of GAA NW-FET is less impacted by the SR scattering. FinFET shows smaller $d \mu_{e f f} / d T$ $\left(\sim-0.162 \mathrm{~cm}^{2} / \mathrm{V} \cdot \mathrm{s} /{ }^{\circ} \mathrm{C}\right)$ and higher mobility degradation coefficient $\alpha(0.96)$, compared to that of GAA NW-FET $\left(\sim-0.016 \mathrm{~cm}^{2} / \mathrm{V} \cdot \mathrm{s} /{ }^{\circ} \mathrm{C}\right.$ and 0.6 , respectively). This means that the carrier transport in GAA NW-FET is not mainly limited by SR scattering but phonon scattering at high $N_{i n v}$. In the case of FinFET, the SR scattering mainly limits the carrier transport at high $N_{\text {inv }}$.

Author Contributions: Data curation, S.K., D.J. and J.W.L.; Formal analysis, S.K., D.J., J.K., R.R., B.P., J.M., H.M., T.C., N.H. and J.W.L.; Funding acquisition, B.P. and N.H.; Investigation, R.R., J.M., H.M. and T.C.; Project administration, B.P. and N.H.; Validation, R.R., J.M., H.M. and T.C.; Visualization, S.K., D.J., J.K. and J.W.L.; Writing-original draft, S.K., D.J. and J.W.L. All authors have read and agreed to the published version of the manuscript.

Funding: This research was supported by the MOTIE (Ministry of Trade, Industry \& Energy (10067808)) and KSRC (Korea Semiconductor Research Consortium) support program for the development of the future semiconductor device, and the National Research Foundation of Korea (NRF) grant funded by the KOREA government (MSIT) (2019R1F1A1060687).

Acknowledgments: The imec sub-14 nm program members and the amsimec (test lab) are acknowledged for their support.

Conflicts of Interest: The authors declare no conflicts of interest.

\section{References}

1. Colinge, J.-P. FinFETs and Other Multi-Gate Transistors; Springer US: New York, NY, USA, 2008; Volume 73.

2. Nagy, D.; Indalecio, G.; García-Loureiro, A.J.; Elmessary, M.A.; Kalna, K.; Seoane, N. FinFET versus gate-all-around nanowire FET: Performance, scaling, and variability. IEEE J. Electron Devices Soc. 2018, 6, 332-340. [CrossRef]

3. Pott, V.; Moselund, K.E.; Bouvet, D.; De Michielis, L.; Ionescu, A.M. Fabrication and characterization of gate-all-around silicon nanowires on bulk silicon. IEEE Trans. Nanotechnol. 2008, 7, 733-744. [CrossRef]

4. Hur, S.-G.; Yang, J.-G.; Kim, S.-S.; Lee, D.-K.; An, T.; Nam, K.-J.; Kim, S.-J.; Wu, Z.; Lee, W.; Kwon, U. A practical Si nanowire technology with nanowire-on-insulator structure for beyond $10 \mathrm{~nm}$ logic technologies. In Proceedings of the 2013 IEEE International Electron Devices Meeting, Washington, DC, USA, 9-11 December 2013; pp. 26.25. 21-26.25. 24.

5. Kuhn, K.J. Considerations for ultimate CMOS scaling. IEEE Trans. Electron Devices 2012, 59, $1813-1828$. [CrossRef]

6. Takato, H.; Sunouchi, K.; Okabe, N.; Nitayama, A.; Hieda, K.; Horiguchi, F.; Masuoka, F. Impact of surrounding gate transistor (SGT) for ultra-high-density LSI's. IEEE Trans. Electron Devices 1991, 38, 573-578. [CrossRef]

7. Mertens, H.; Ritzenthaler, R.; Hikavyy, A.; Kim, M.-S.; Tao, Z.; Wostyn, K.; Chew, S.A.; De Keersgieter, A.; Mannaert, G.; Rosseel, E. Gate-all-around MOSFETs based on vertically stacked horizontal Si nanowires in a replacement metal gate process on bulk Si substrates. In Proceedings of the 2016 IEEE Symposium on VLSI Technology, Honolulu, HI, USA, 14-16 June 2016; pp. 1-2.

8. Ritzenthaler, R.; Mertens, H.; De Keersgieter, A.; Mitard, J.; Mocuta, D.; Horiguchi, N. Isolation of nanowires made on bulk wafers by ground plane doping. In Proceedings of the 2017 47th European Solid-State Device Research Conference (ESSDERC), Leuven, Belgium, 11-14 September 2017; pp. 300-303. 
9. Kim, S.-Y.; Kim, Y.M.; Baek, K.-H.; Choi, B.-K.; Han, K.-R.; Park, K.-H.; Lee, J.-H. Temperature dependence of substrate and drain-currents in bulk FinFETs. IEEE Trans. Electron Devices 2007, 54, 1259-1264. [CrossRef]

10. Ma, C.; Wang, H.; Zhang, C.; Zhang, X.; He, J.; Zhang, X. Temperature dependence of the interface state distribution due to hot carrier effect in FinFET device. Microelectron. Reliab. 2010, 50, 1077-1080. [CrossRef]

11. Zhu, W.; Ma, T. Temperature dependence of channel mobility in HfO/sub 2/-gated NMOSFETs. IEEE Electron Device Lett. 2004, 25, 89-91. [CrossRef]

12. Quay, R.; Moglestue, C.; Palankovski, V.; Selberherr, S. A temperature dependent model for the saturation velocity in semiconductor materials. Mater. Sci. Semicond. Process. 2000, 3, 149-155. [CrossRef]

13. Goel, N.; Tripathi, A. Temperature effects on threshold voltage and mobility for partially depleted SOI MOSFET. Int. J. Comput. Appl. 2012, 42, 56-58.

14. Roy, K.; Mukhopadhyay, S.; Mahmoodi-Meimand, H. Leakage current mechanisms and leakage reduction techniques in deep-submicrometer CMOS circuits. Proc. IEEE 2003, 91, 305-327. [CrossRef]

15. Chiarella, T.; Kubicek, S.; Rosseel, E.; Ritzenthaler, R.; Hikavyy, A.; Eyben, P.; De Keersgieter, A.; Kim, M.-S.; Chew, S.-A.; Schram, T. Towards high performance sub-10nm finW bulk FinFET technology. In Proceedings of the 2016 46th European Solid-State Device Research Conference (ESSDERC), Lausanne, Switzerland, 12-15 September 2016; pp. 131-134.

16. Lee, J.W.; Simoen, E.; Veloso, A.; Cho, M.J.; Boccardi, G.; Ragnarsson, L.-Å.; Chiarella, T.; Horiguchi, N.; Groeseneken, G.; Thean, A. Sidewall crystalline orientation effect of post-treatments for a replacement metal gate bulk fin field effect transistor. Acs Appl. Mater. Interfaces 2013, 5, 8865-8868. [CrossRef] [PubMed]

17. Woo Lee, J.; Ju Cho, M.; Simoen, E.; Ritzenthaler, R.; Togo, M.; Boccardi, G.; Mitard, J.; Ragnarsson, L.-Å.; Chiarella, T.; Veloso, A. 1/f noise analysis of replacement metal gate bulk p-type fin field effect transistor. Appl. Phys. Lett. 2013, 102, 073503. [CrossRef]

18. Shrivastava, M.; Agrawal, M.; Mahajan, S.; Gossner, H.; Schulz, T.; Sharma, D.K.; Rao, V.R. Physical insight toward heat transport and an improved electrothermal modeling framework for FinFET architectures. IEEE Trans. Electron Devices 2012, 59, 1353-1363. [CrossRef]

19. Chain, K.; Huang, J.-H.; Duster, J.; Ko, P.K.; Hu, C. A MOSFET electron mobility model of wide temperature range (77-400 K) for IC simulation. Semicond. Sci. Technol. 1997, 12, 355-358. [CrossRef]

20. Ortiz-Conde, A.; Sánchez, F.G.; Liou, J.J.; Cerdeira, A.; Estrada, M.; Yue, Y. A review of recent MOSFET threshold voltage extraction methods. Microelectron. Reliab. 2002, 42, 583-596. [CrossRef]

21. Elewa, T.; Balestra, F.; Cristoloveanu, S.; Hafez, I.M.; Colinge, J.-P.; Auberton-Herve, A.-J.; Davis, J.R. Performance and physical mechanisms in SIMOX MOS transistors operated at very low temperature. IEEE Trans. Electron Devices 1990, 37, 1007-1019. [CrossRef]

22. Iijima, R.; Takayanagi, M. Experimental and theoretical analysis of factors causing asymmetrical temperature dependence of V t in High-k Metal gate CMOS with capped High-k techniques. In Proceedings of the 2008 IEEE International Electron Devices Meeting, San Francisco, CA, USA, 15-17 December 2008; pp. 1-4.

23. Lyu, J.-S.; Nam, K.-S.; Lee, C. Determination of the interface trap density in metal oxide semiconductor field-effect transistor through subthreshold slope measurement. Jpn. J. Appl. Phys. 1993, 32, 4393. [CrossRef]

24. Banqueri, J.; Lopez-Villanueva, J.; Gamiz, F.; Carceller, J.; Lora-Tamayo, E.; Lozano, M. A procedure for the determination of the effective mobility in an N-MOSFET in the moderate inversion region. Solid-State Electron. 1996, 39, 875-883. [CrossRef]

25. Takagi, S.-I.; Toriumi, A.; Iwase, M.; Tango, H. On the universality of inversion layer mobility in Si MOSFET's: Part I-effects of substrate impurity concentration. IEEE Trans. Electron Devices 1994, 41, 2357-2362. [CrossRef]

26. Lee, C.; Nishimura, T.; Tabata, T.; Lu, C.; Zhang, W.; Nagashio, K.; Toriumi, A. Reconsideration of electron mobility in Ge n-MOSFETs from Ge substrate side-Atomically flat surface formation, layer-by-layer oxidation, and dissolved oxygen extraction. In Proceedings of the 2013 IEEE International Electron Devices Meeting, Washington, DC, USA, 9-11 December 2013; pp. 2.3.1-2.3.4.

27. Lee, J.W.; Jang, D.; Mouis, M.; Kim, G.T.; Chiarella, T.; Hoffmann, T.; Ghibaudo, G. Mobility analysis of surface roughness scattering in FinFET devices. Solid-State Electron. 2011, 62, 195-201. [CrossRef]

28. Deleonibus, S. Electronic Devices Architectures for the NANO-CMOS Era; CRC Press: Boca Raton, FL, USA, 2019.

(C) 2020 by the authors. Licensee MDPI, Basel, Switzerland. This article is an open access article distributed under the terms and conditions of the Creative Commons Attribution (CC BY) license (http://creativecommons.org/licenses/by/4.0/). 